\title{
PENDIDIKAN AKHLAK KEPADA ANAK DENGAN METODE HABITUASI (Kajian Hadits Dalam Perspektif Psikologi)
}

\author{
Idail Uzmi Fitri Umami \\ Pascasarjana UIN Sunan Kalijaga Yogyakarta \\ e-mail: umamiidail123@gmail.com
}

\begin{abstract}
Moral education for children is very important because children are the next generation of religion, nation and state, imagine how a country would become if its successor or leader does not have morals and morals, of course, what happens is chaos in that country. Moral education for someone should be early because morality is the embodiment of personality that is nurtured from the beginning, fostering good moral character for children certainly starts from the smallest environment of his life, namely the family environment. But the problem that arises is how to educate children correctly and effectively, a term known in children's temperament is the tabula rasa expression which means the child is born like blank paper and innocently does not have any scribble at all that the child carries nothing when born, so this It is the duty of parents to direct their children to the right path or to the wrong road.
\end{abstract}

Keywords: Akhlakul Karimah, Hadith, Behaviorism 


\begin{abstract}
Abstrak
Pendidikan akhlak bagi anak sangat penting karena anak merupakan generasi penerus agama, bangsa dan Negara, bayangkan bagaimana jadinya sebuah Negara bila penerusnya atau pemimpinya tidak mempunyai moral dan akhlak, tentunya yang terjadi adalah kekacauan di negara tersebut. Pendidikan akhlak untuk seseorang hendaklah sedari dini karena akhlak merupakan perwujudan kepribadian yang dibina dari awal, pembinaan Akhlak karimah bagi anak tentunya berawal dari lingkungan terkecil dari kehidupannya yaitu lingkungan keluarga. Tapi permasalahan yang muncul adalah bagaimana cara mendidik anak dengan benar dan efektif, sebuah istilah dikenal dalam perangai anak adalah ungkapan tabula rasa yang berarti anak lahir seperti kertas kosong dan polos tidak memiliki coretan sama sekali yaitu anak tidak membawa apa-apa ketika dilahirkan, jadi ini merupakan tugas orang tua mau mengarahkan anaknya kejalan yang mana entah ke jalan yang benar atau ke jalan yang salah.
\end{abstract}

Kata Kunci: Akhlakul Karimah, Hadits, Behaviorisme 


\section{A. Pendahuluan}

Pendidikan Akhlak yang diberikan kepada anak-anak pada masakecil akan bersifat menentukan bagi kehidupan bermasyarakat mereka dikemudian hari. Apabila seorang anak sudah menerima didikan Akhlak sejak kecil dengan pembiasaan oleh orang tuanya, maka haliniberartibahwa anak tersebut telah dilengkapi dengan sesuatu kekuatan rohani untukmenghadapi pengaruh-pengaruh buruk yang akan dijumpainyadikemudian hari. Betapabesar malapetaka yang akan menimpa kehidupanseorang anak pada masa pertumbuhan sampaimenjadi dewasa, apabilasama sekali tidak diberikan pelndidikan Akhlak pada masa kecilnya.

Bentuk pendidikan agama yang perlu diberikan kepada anak salah satunya pendidikan Akhlak, karena akhlak merupakan perwujudan dari watak seseorang dan merupakan kunci sukses dalam berinteraksi kepada sesama manusia dalam bentuk ibadah horizontal (Habluminan nas). Oleh karena itu pendidikan akhlak merupakan salah satu pendidikan urgent pada anak.

Manusia dan akhlak merupakan satu kesatuan yang tidak bisa dipisahkan dari kehidupan sehari-hari, karena akhlak merupakan cerminan dari watak dari seseorang dan bisa dikatakan perwujudan dari kualitas hati, bila seorang memiliki hati yang baik maka otomatis akhlaknya baik, dan apabila hatinya kotor maka akhlaknya juga buruk.

Tetapi akhlak juga bisa dipengaruhi oleh faktor lingkungan seperti faktor keluarga dan faktor pergaulan, peran keluarga sendiri sangat urgen pengaruhnya terhadap pembentukan kepribadian anak sebelum memasuki bangku sekolah, karena keluarga merupakan tahap paling awal bagi anak untuk menemukan pengetahuan mana hal yang baik dan hal yang buruk.

Pembinaan akhlak sangatlah perlu sedari masih kecil karena kepribadian terbentuk dari masa kanak-kanak, pendidikan akhlak juga dimulai dari ruanglingkup terkecilsepertidariranah keluarga, karena anak mendapatkan pengetahuan pertama dari keluarga dan juga pola asuh keluarga sangatlah penting kaitannya terhadap anak, apabila pola asuh orang tua kepada anak baik yaitu berlandaskan Alqur'an dan sunnah tentunya akan membuahkan kepribadian anak akan baik begitu juga sebaliknya.

\section{B. Pengertian Akhlak}

Menurut bahasa (etimologi) perkataan akhlak ialah bentuk jamak dari khuluq (khuluqun) yang berarti budi pekerti, perangai, tingkah laku 
atau tabi'at. ${ }^{1}$ Akhlak adalah keadaan batin seseorang yang menjadi sumber lahirnya perbuatan dimana perbuatan itu dilahir dengan mudah tanpa memikirkan untung rugi. Orang yang berakhlak baik, melakukan kebaikan secara spontan tanpa pamrih apapun, demikian juga orang yang berakhlak buruk, melakukan keburukan secara spontan tanpa mempertimbangkan akibat bagi dirinya maupun bagi yang dijahati. $^{2}$

Adapun menurut Imam Ghazali memberi pengertian akhlak sebagai berikut:

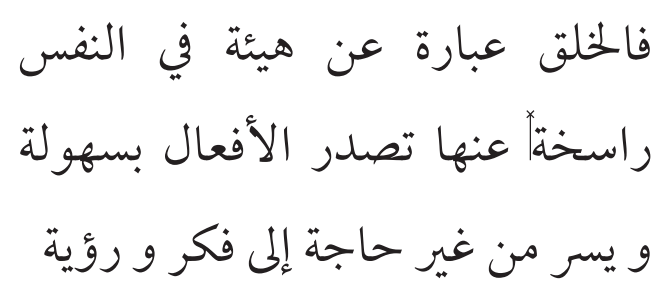

Akhlak adalah sifat yang tertanam dalam jiwa yang memunculkan perbuatan-perbuatan yang spontan, tanpa harus memerlukan pemikiran dan pertimbangan ${ }^{3}$

Dari pengertian di atas dapat di simpulkan bahwa akhlak merupakan sifat yang terpatri dalam diri seseorang yang merupakan cerminan dari

1 A. Mustofa, Akhlak
Tasawuf,(Bandung:Pustaka Setia, 1997), 11.

2 Shomiyatun, Pendidikan Anak Dalam Keluarga, (Yogyakarta: Mandiri Graffindo Press, 2013), 61.

3 Yunahar Ilyas, Kuliah Akhlak, (Yogyakarta: Pustaka pelajar, 2011), 1. wataknya sehingga ketika ia berbuat maka secara spontan ia lakukan tanpa harus memikirkannya terlebih dahulu.

Sehingga akhlak terbagi menjadi dua yaitu akhlakul karimah dan akhlak madzmumah. Akhlak mahmudah merupakan perwujudan sikap mulia seperti menolong, rajin ibadah, berbakti kepada kedua orang tua dan lain sebagainya, sedangkan akhlak madzmumah merupakan perwujudan sikap tercela, seperti bolos sekolah, malas, mencuri, durhaka kepada kedua orang tua dan lain sebagainya.

Maka dari itu akhlakul karimah inilah yang mesti diajarkan kepada anak karena anak merupakan generasi penerus ketika dia sudah dewasa nanti. Semua komponen haruslah ikut serta dalam pembentukan akhlak mulia tersebut termasuk yang dasar yaitu peran keluarga dan lingkungan sekolah.

\section{Pendidikan Akhlakul Karimah}

Maka dalam rangka mendidik akhlak kepada anak-anak, selain harus kita berikan keteladanan yang tepat, juga harus kita tunjukkan tentang bagaimana kita harus bersikap, bagaimana kita harus menghormati dan seterusnya. Kalau kita ingin dihormati oleh orang lain, terutama oleh anak-anak kita sendiri, tentulah 
harus kita awali dari kita sendiri untuk berbuat baik kepada sesama dan berbakti kepada kedua orang tua kita. Maka dengan mengawalinya demikian, niscaya orang lain pun akan menghormati kita dan anak-anak pun akan berbakti kepada kita. ${ }^{4}$

Seperti yang telah dijelaskan di atas mendidik anak tentunya tidak hanya tentang metode perintah tapi kita sendiri tidak melakukannya seperti contohnya menyuruh anak sholat tepat waktu sedangkan kita tidak melakukannya bahkan ketika kita menyuruh anak untuk sholat malah kita sendiri yang sedang asyik nonton tv, ini merupakan contoh pendidikan akhlak yang salah. Lantas bagaimanakah pendidikan akhlak yang benar?

Sebagaimana halnya masalah ibadah, maka masalah akhlak pun harus diberikan dan dibiasakan semenjak kecil kepada anak. Teori keilmuan yang beraneka macam belum menjamin seseorang dapat mengamalkan peribadatan dan akhlak ini dengan baik dan benar tanpa dibarengi dengan pengalaman berupa pembiasaan dalam kehidupan seharihari. Maka dengan usaha pembiasaaan pada diri anak secara dini, lebih bisa

\footnotetext{
4 Shomiyatun, Pendidikan Anak Dalam Keluarga, (Yogyakarta: Mandiri Graffindo Press, 2013), 30-31.
}

diharapkan akhlakul karimah akan benar-benar membentuk pribadi pada diri anak. ${ }^{5}$

\section{Pendidikan Akhlakul Karimah Dengan MenggunakanMetode Pembiasaan}

Pembiasaan adalah upaya praktis dalam pendidikan dan pembinaan anak. Hasil dari pembiasaan yang dilakukan seorang pendidik adalah terciptanya suatu kebiasaan bagi anak didiknya. "kebiasaan itu adalah suatu tingkah laku tertentu yang sifatnya otomatis, tanpa direncanakan dulu, serta berlaku begitu saja tanpa dipikir lagi”. Seorang anak yang terbiasa mengamalkan nilai-nilai ajaran islam lebih dapat diharapkan dalam kehidupannya nanti akan menjadi seorang dalam kehidupannya nanti akan menjadi seorang muslim yang saleh. ${ }^{6}$ Pembiasaan merupakan proses membuat sesuatu agar seseorang menjadi terbiasa.Metode Pembiasaan ini merupakan cara yang sangat efektif dalam menanamkan nilai-nilai moral ke dalam jiwa anak. ${ }^{7}$ 
a. Hadits tentang pembiasaan terhadap akhlak karimah

$$
\begin{aligned}
& \text { ا ـحدثنا محمد بن بكر، قال : حدثنا ابن بشار، } \\
& \text { قال : حدثنا أبو عاصم، قال : أخبرنا ابن } \\
& \text { جريح، قال : أخبرني عمرو بن أبي سفيان: } \\
& \text { أن عمرو بن عبد الله بن صفوان أخبره عن } \\
& \text { كلدة بن حنبل: أن صفوان بن أمية بعثه الى } \\
& \text { رسول الله صلى الله عليه و سلم بلبن وجداية } \\
& \text { و ضغابيس و النبي صلى الله عليه و سلم بأعلى } \\
& \text { مكة فدخلت و لم أسلم فقال ارجع فقل السلام } \\
& \text { عليكم ( رواه أبو دودو ترميذي) }
\end{aligned}
$$

Artinya: Kaladah Bin Hanbal meriwayatkan bahwa ia diutus oleh Shafwan Bin Umayyah kepada rasulullah membawa susu, anak kijang, dan ketimun kecil. Sementara itu nabi sedang berada di ketinggian Mekkah. Ia berkata, "aku masuk tanpa mengucapkan salam terlebih dahulu" lalu beliau bersabda, "keluar dulu, lalu ucapkan salam." (H.R.Abu Dawud dan At-Tirmidzi).

b. Kritik sanad

1. Muhammad Bin Bakar Muhammad bin bakar
mempunyai nama lengkap

8 Jawami'ul Kalim Online, diakses tanggal 17 November, 16:17 WIB.
Muhammad bin bakarbin Muhammad bin abdul rozzak, sedangkan nama terkenalnya adalah Muhammad bin dassah al-basyri dan mempunyai nama kunyah abu bakar, keturunan nasab bashrah dan beliau lahir tahun 346. Guru-gurunya antara lain : Ibrahim bin Abdullah, abu dawud dan lain-lain, nama murid-muridnya antara lain : Ahmad bin Abdullah, Ahmad bin atho', Ahmad bin Muhammad al-malainy dan lain-lain. Berdasarkan dari gurugurunya bahwa Muhammad bin bakar tsiqqoh

2. Abu Daud

Nama lengkapnya Abu Daud As-sajastani memiliki kuniyah bernama abu daud, memiliki nasab al-azdi as-sajastani tinggal di basrah dan wafat di basrah pada tahun $202 \mathrm{H}$. nama-nama gurunya antara lain : Abdullah bin yahya ar-razi, ahmad bin abu bakar al-parisyi, ahmad bin Ibrahim al-maushuli dan lainlain, sedangkan memiliki murid di antaranya : ishaq bin Ibrahim ad-diry, ishaq bin Mansur alkusaj, zaid bin akhzam at-tholy dan lain-lain. Abu daud dalam keterangannya bersifat tsiqqoh hafidz 
3. Ibnu Basyar

Nama lengkapnya Muhammad bin basyar bin utsman bin daud bin kaisan, memiliki nama terkenal Muhammad basyar al-idi, mempunyai kuniyah abu bakar dan bernasabkan al'idy al-basyri. Beliau tinggal di basrah wafat pada tahun 167 $\mathrm{H}$, nama-nama gurunya antara lain : ahmad bin al-miqdam al-ajali, azhar bin qosim arrosi, azhar bin saad al-bahily dan lain-lain, memiliki murid antaranya : ahmad bin Abdullah al-arari, ahmad bin ali al amwi, ahmad bin hambal asy-syaiti dan lain-lain. Abu fatah al azdi mengatakan bahwa ibnu basyar adalah khair dan saduq.

4. Abu 'Asim

Memiliki nama lengkap dikhaq bin mukhlid bin dikhaq bin muslim bin dikhaq, nama terkenalnya Ad-dikhaq bin mukhlid An-nabil bergelar Annabil dan memiliki kuniyah abu asim, beliau tinggal di basrah dan wafat pada tahun $112 \mathrm{H}$. memiliki guru di antaranya : ayyan bin sumu'ah al-anshory, Abu jarroh al-bahdzy, Abu bakar bin abu sibroh al-farisi dan lainlain sedangkan memiliki murid di antaranya : abu bakar bin abu nadir, abu bakarbin Muhammad al-bahily, ahmad bin Ibrahim addauriqy dan lain-lain. Abu bakar al-baihaqi mengatakan di kitab as-sunanul kubro bahwa beliau tsiqqoh

5. Ibnu jarih

Memiliki nama lengkap Abdul Malik bin abdul aziz bin jarih, memiliki nama terkenal ibnu jarih Al-makky, mempunyai gelar ibnu jarih, bernasabkan alfarisyi al-umuy al-makky, beliau tinngal di bagdad wafat pada tahun $74 \mathrm{H}$. beliau memiliki Guru di antaranya : Ayyan bin abu abbas al-idy, ayyan bin salih al-parisy, abu bakar bin abdurrohman al-makhzumy dan lain-lain sedangkan memiliki murid di antaranya : ayyan bin taglib al-jariry, abu bakar bin abu sibroh al parisyi, ahmad bin Mansur al rumady dan lain-lain abu bakar albaihaqy menyebutkan di dalam ma'rifatus sunan wal atsar bahwa beliau tsiqqoh

6. Umar Bin Abu Sofyan

Memiliki nama lengkap umar bin abu sofyan bin abdur rohman, nama terkenalnya adalah umar bin abu sufyan al-farisyi, memiliki gelar Ibnu abu sofyan dan memiliki nasab 
al-farisyi, al-jumhy, al-makky tinggal di mekkah. Beliau memiliki guru di antaranya : umayyah bin safwan al-akbar, umayah bin safwan al-asgar, abu hurairah ad-dausy dan lain-lain, sedangkan memiliki murid antaranya : isma'il bin umayyah al-umuy, zakariya bin ishaq al-makky, Abdullah bin al-mubarok al-handzaly dan lain-lain. Ibnu hajar al-asqolany menyebutkan pada takrib bahwa beliau tsiqqoh.

7. Umar Bin Abdullah

Memiliki nama lengkap Umar bin Abdullah bin Sofyan bin Khalaf, nama terkenalnya Umar bin Abdullah al-farisy bernasabkan al-farisy al jumhy al-makky dan tinggal di madinah dan mekkah. Memiliki guru di antaranya; umayyah bin saofyan al-akbary, kaldah bin hanbal aljumhy, yazid syiban al-azdy dan lain-lain sedangkan memiliki murid : sofyan bin ayyinah alhilaly, umar bin abu sofyan alfarisy, umar bin dinar al-jumhy. Ibnu hajar mengatakan di takrib bahwa beliau soduq dan syarif.

\section{Kaladah}

Memiliki nama lengkap kaldah bin Abdullah bin al-hanbal bin malik, nama terkenalnya adlah kaldah bin hanbal al-jumhy bernasabkan al-jumhy alaslamy al-makky, beliau tinggal di mekkah dan yaman, beliau merupakan sahabat rasulullah. Memiliki guru sofyan bin umayyah al-farisy dan murid umayyah bin sofyan al-asgory, umar bin Abdullah al-farisy. Imam bukhari mengatakan bahwa beliau sahabat Nabi Muhammad SAW. Jalur sanad hadis tersebut dapat dideskripsikan sebagai berikut:
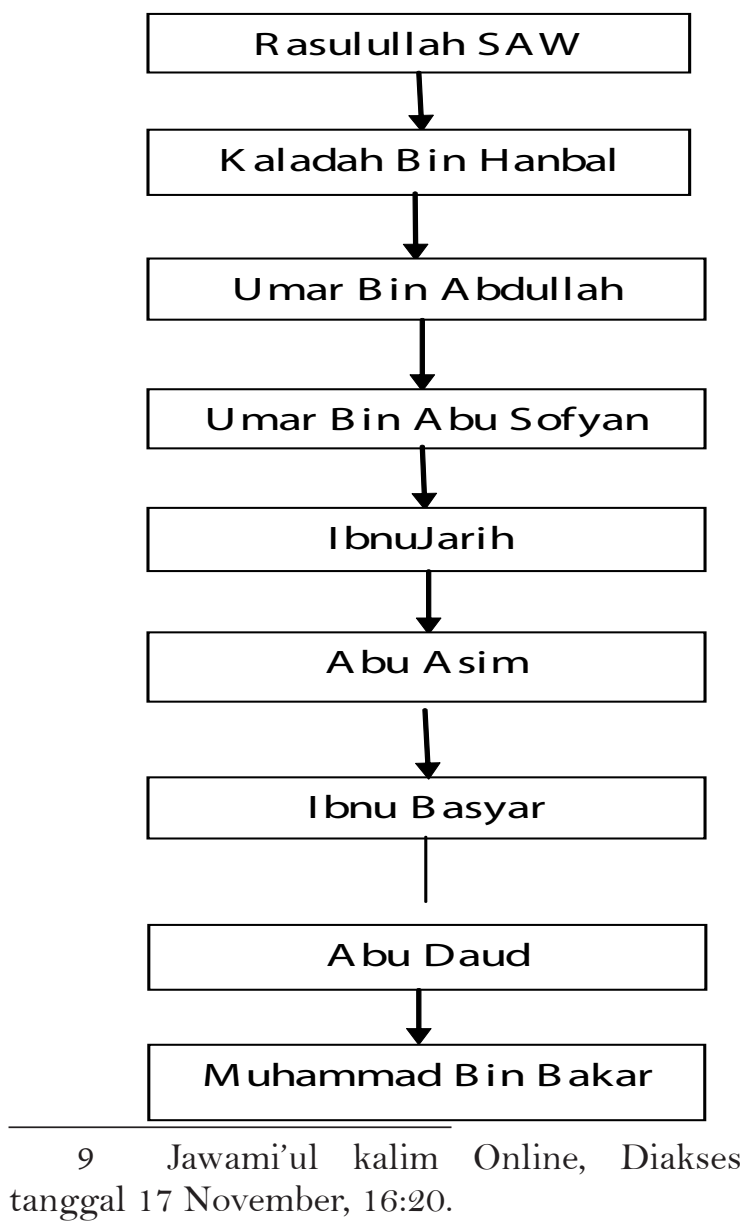
c. Kajian Matan Hadits

Pada pembahasan matan hadits tersebut menjelaskan tentang kaladah yang tidak mengucapkan salam ketika mendekati Nabi Muhammad, Oleh karena itu Nabi bersabda untuk menyuruhnya keluar dan kembali mengucapkan salam. Tapi nabi Muhammad tidak memarahi kaladah yang tidak mengucapkan salam ketika masuk.Hal yang di lakukan tersebut mengajarkan kita untuk mengulangi perilaku baik agar menjadi kebiasaan yang baik, karena kebaikan sifatnya akan menetap bila dibiasakan.

Pada hadits tersebut terdapat lafadz fiil amar (إرجع yang berarti kembalilah artinya kaladah disuruh keluar dan masuk lagi dengan mengucapkan salam. Ucapan salam seorang muslim merupakan ibadah dan bernilaipahalayangmenunjukkan doa untuk sesame muslim dan yang mendengar salam juga wajib untuk membalasnya sebagai balasan kebaikan. Ini merupakan perilaku baik yang sepatutnya dibiasakan oleh kita seorang muslim untuk menerapkannya di kehidupan seharihari.

Ciri-ciri hadits sahih atau hasan adalah tidak bertentangan dengan dalil lainnya baik al-Qur'an maupun hadits yang lain, ataupun ada dalil yang mendukung isi kandungan hadits tersebut.Hadits lain yang mendukung kandungan makna hadits tersebut antara lain :

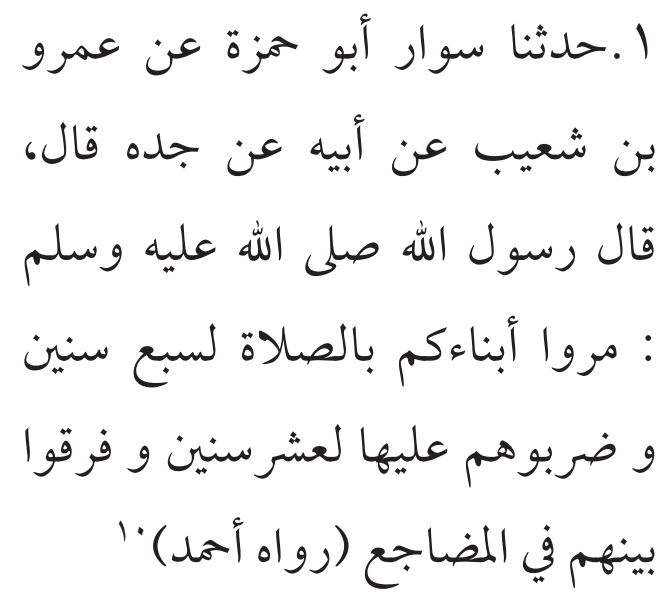

Artinya:Sawwar Abu Hamzah menceritakan kepada kami dari amr bin syuaib dari bapaknya dari kakeknya, rasulullah SAW: suruhlah anakmu mendirikan shalat ketika berumur tujuh tahun dan pukullah mereka karena meninggalkannya, ketika ia berumur sepuluh tahun pisahkanlah tempat tidur mereka. (H.R. Ahmad)

Hadits diatas memiliki kandungan makna yang hampir mirip dengan pembahasan hadits diatas yang berkaitan tentang pembentukan perilaku organismedengan pembiasaan atau conditioning, pada hadits tersebut menjelaskan tentang pembiasaan terhadap anak untuk mendidik dia mendirikan sholat pada umur tahun

10 Maktabah Syamilah, Kitab Musnad Ahmad, No. 6927. 
karena pendidikan kepribadian lebih bagus ditanamkan sejak dini. Karena pada masa kanak-kanak itu masa dimana anak membutuhkan pendidikan yang akan membentuk kepribadian dan akhlaknya sampai dewasa.

Pada hadits diatas juga sangat menekankan pendidikan akhlak karimah dengan perintah sholat sehingga nabi menyuruh orang tua untuk memukulnya bila tidak mentaati perintah sholat tersebut, ini membuktikan bahwa orang tua juga punya peran penting dalam pendidikan anak. Tujuan hadits ini agar orang tua membiasakan anaknya mengerjakan sholat, pada hadits ini juga terdapat teori conditionin classical yang bentuk stimulusnya adalah perintah orang tua untuk mengerjakan sholat dan pukulan orang tua kepada anak jikalau anak tidak mentaatinya, setiap stimulus tentunya menghendaki respons, dan respons tersebut adalah ketaatan anak.

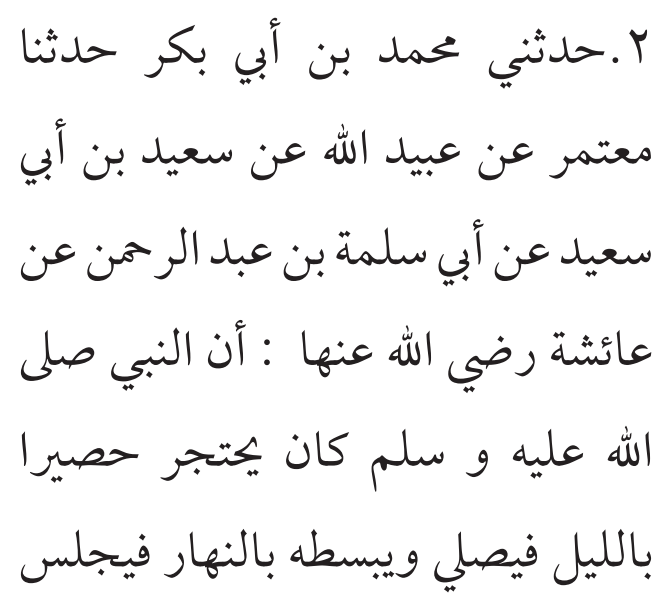

عليه فجعل الناس يثوبون إلى النبي صلى الله عليه و سلم فيصلون بصلاته حتى كثروا فأقبل فقال ( يا أيها الناس خذوا من الأعمال ما تطيقون فإن الله لا يمل حتى تملوا و إن أحب الأعهال إلى الله ما دام وإن قل ). (رواه حاكم) ' Hadits tersebut menjelaskan tentang perilaku baik yang bersifat berkelanjutan artinya menjadi pembiasaan dalam perilakunya, perilaku tersebut merupakan perilaku yang disukai oleh Allah walaupun sedikit. Ini juga bisa dikategorikan perilaku yang istiqomah.

d. Kontekstualisasi Hadits tersebut dengan psikologi

Psikologi merupakan ilmu yang mempelajari tentang jiwa dan perilaku manusia, tentunya apabila pembahasan hadits ini dikaitkan dengan psikologi memiliki hubungan atau titik temu didalamnya, Pembahasan tentang pendidikan Akhlakul Karimah kepada Anak dengan metode pembiasaan ini berelevansi dengan cabang psikologi yang dikenal dengan Behaviorisme, behaviorisme merupakan paham yang berpendapat bahwa pembentukan perilaku itu dipengaruhi oleh faktor

.Ibid 
dari luar baik dari lingkungan keluarga, sekolah maupun lingkungan masyarakat.

Dan madzhab behaviorisme dalam ilmu Psikologi ini memiliki beberapa bagian dan salah satunya adalah teori Classical conditioning.Sebuah teori psikologiyangmembentukkepribadian manusia, yang dipelopori oleh ilmuwan bernama Ivan Petrovich Pavlov dengan teorinya yang bernama teori classical conditioning yang menitik beratkan stimulus dan respons sebagai teori pembentukan kepribadian individu.

Salah satu cara pembentukan perilaku yang dapat ditempuh dengan conditioning atau kebiasaan yaitu dengan cara membiasakan diri untuk berperilaku seperti yang diharapkan, akhirnya akan terbentuklah perilaku tersebut. ${ }^{12}$ Pembiasaan klasikal merupakan tipe belajar yang menekankan stimulus netral yang memerlukan kapasitas untuk merangsang respon secara orisinal terangsang oleh stimulus lain. Proses ini dinamakan juga respont conditioning yang pertama kali diperkenalkan oleh Ivan Pavlov pada tahun $1903^{13}$

12 Bimo Walgito, Pengantar Psikologi Umum, (Yogyakarta: Andi Yogyakarta Press, 2010), 14 .

13 Syamsu Yusuf dan Juantika Nurihsan, Teori Kepribadian,(Bandung: PT Remaja Rosdakarya, 2011), 124.
Untuk memahami eksperimen Pavlov, terlebih dahulu harus memahamibeberapa pengertian pokok yang bisa digunakan dalam teori Pavlov sebagai unsur dalam eksperimennya, yaitu sebagai berikut:

1. Unconditioned Stimulus (US): stimulus asli atau netral: stimulus tidak dikondisikan, yaitu stimulus yang langsung menimbulkan respons, misalnya susumembuat bayi berhenti menangis. US disebut juga sebagai perangsang alami atau perangsang wajar, yaitu perangsang yang secara alami dan secara wajar dapat menimbulkan respons pada organisme.

2. Conditioning Stimulus (CS): stimulus bersyarat, yaitu stimulus yang tidak langsung menimbulkan respons, CS perlu dipasangkan secara terus menerus agar menimbulkan respons. Misalnya, elusan ibu menyebabkan bayi berhenti menangis jika selalu diiringi dengan pemberian susu. Disebut juga dengan perangsang bersyarat $=$ perangsang tidak wajar $=$ perangsang tidak alami Conditioning Stimulus (CS), yaitu perangsang yang secara alami tidak menimbulkan respons.

3. Unconditioned Respons (UR): disebut perilaku responden (Respondent Behavior) respons 
tidak bersyarat, yaitu respons yang muncul dengan hadirnya US, yaitu bayi berhenti menangis karena ada pemberian susu. Sebutan lain adalah respons tidak bersyarat $=$ respons alami $=$ respons wajar, yaitu respons yang ditimbulkan oleh perangsang tidak bersyarat (Unconditioned Stimulus=UR).

4. Conditioning Respons (CR) : Respons bersyarat, yaitu respons yang muncul dengan hadirnya CS, misalnya, bayi berhenti menangis karena ada elusan ibu, yaitu respons yang ditimbulkan oleh perangsang bersyarat (Conditioed Response $=$ CR). ${ }^{14}$

Dari penjelasan diatas disebutkan bahwa pembentukan kepribadian diawali oleh suatu stimulus kemudian direspons, respons inilah yang menjadi kepribadian bilamana dibiasakan, hal itu terekam pada makna hadits tersebut yang terdapat stimulus dan respons. Pada hadits tersebut bentuk stimulus adalah perintah nabi yang menyuruh kaladah untuk keluar untuk membaca salam dulu sebelum masuk menghampiri Nabi Muhammad dan kaladah merespons dengan mentaati perintah Nabi tersebut.

14 Ujam Jaenuddin, Teori-Teori Kepribadian, (Bandung: Pustaka Setia,2015), 32-33.
Struktur kepribadian dari Pavlov ini bergantung pada respons atau stimulus yang diberikan oleh seseorang. Semakin besar stimulus yang diberikan, respons yang diterima juga akan semakin kuat. Dengan demikian, Pavlov membagi struktur kepribadian menjadi dua, yaitu sebagai berikut:

a. Tingkah laku responden. Respons yang dihasilkan organisme untuk menjawab stimulus secara spesifik berdasarkan respns yang diberikan.

b. Tingkah laku operan. Respons yang dimunculkan organisme tanpa stimulus spesifik yang langsung memaksa terjadinya respons itu. Organisme dihadapkan pada pilihan-pilihan respons yang dipakai untuk menanggapi suatu stimulus. ${ }^{15}$

Pavlov menyatakan bahwa kepribadian dapat dipahami dengan mempertimbangkan tingkah laku dalam hubungan yang terus menerus dengan lingkungannya. Cara yang efektif untuk mengubah dan mengontrol tingkah laku adalah penguatan. Artinya, dengan diberi penguatan yang positif, tingkah laku seseorang akan berubah dan terkontrol

15 Alwisol, Psikologi Kepribadian, (Malang: Universitas Muhammadiyah Malang, 2004),402. 
dengan baik. ${ }^{16}$ Penjelasan tersebut sesuai dengan cerita pada hadits di atas yang dialami oleh Kaladah. Dimana kaladah merespons dari stimulus berupa perintah nabi Muhammad yang menyuruhnya keluar untuk mengulangi cara masuknya dengan mengucapkan salam.

\section{E. Penutup}

Pendidikan akhlakul karimah untuk seseorang hendaklah sedari dini karena akhlak merupakan perwujudan kepribadian yang dibina dari awal, pendidikan perilaku atau Akhlak karimah bagi anak tentunya berawal dari lingkungan terkecil dari kehidupannya yaitu lingkungan keluarga dan meluas ke lingkungan luar seperti sekolah dan kehidupan masyarakat.

Karena pengaruh lingkungan luar tidak bisa dilepaskan dari pembentukan perilaku manusia, dalam psikologi hal tersebut dinamakan mazhab behaviorisme yaitu paham yang berpendapat bahwa individu dibentuk perilakunya dari faktor luar seperti lingkungan keluarga dan lain sebagainya, tapi untuk masa anak-anak maka cenderung yang berpengaruh adalah lingkungan keluarga. Dan

6 Ujam Jaenuddin, Teori-Teori Kepribadian, (Bandung: Pustaka Setia,2015), 34. salah satu cabang pemikiran mazhab behaviorisme adalah teori conditioning classical yang dipelopori oleh ilmuwan bernama Ivan Pavlov.

Dia berpendapat bahwa perilaku seseorang terbentuk karena pembiasaan, artinya pembiasaan yang terus-menerus melalui stimulus dan ditanggapi oleh respons, bila stimulus dibiasakan maka perilaku respons itu juga akan terbiasa dan menjadi perilaku yang tetap bila terus diulangi. 


\section{Daftar Pustaka}

Alwisol, Psikologi Kepribadian, (Universitas Muhammadiyah Malang, 2004)

Ilyas, Yunahar, Kuliah Akhlak, (Yogyakarta, Pustaka pelajar, 2011)

Jaenuddin, Ujam, Teori-Teori Kepribadian, (Bandung: Pustaka Setia, 2015)

Mustofa, A, Akhlak Tasawuf, (Bandung: Pustaka Setia 1997)
Shomiyatun, Pendidikan Anak Dalam Keluarga, (Yogyakarta, Mandiri Graffindo Press, 2013)

Syamilah, Maktabah, Kitab Musnad Ahmad, No. 6927.

Walgito, Bimo, Pengantar Psikologi Umum, (Yogyakarta: Andi Press, 2010)

Yusuf,

Syamsu, dan Nurihsan,Juantika, Teori Kepribadian,(Bandung:PTRemaja Rosdakarya, 2011) 